\title{
HOMEM RAZÃO E MULHER EMOÇÃO: UMA ANÁLISE DA RELAÇÃO DICOTÔMICA ENTRE HOMENS E MULHERES NA VISÃO DOS ASSENTADOS(AS)
}

\section{MAN REASON AND WOMAN EMOTION: AN ANALYSIS OF THE DUAL RELATION BETWEEN MEN AND WOMEN IN THE VISION OF THE SETTLERS}

\author{
Fernanda Chiozzini Martins Suarez, ${ }^{1}$ \\ Júnia Marise Matos Sousa ${ }^{2}$
}

\section{RESUMO}

O presente artigo convida o leitor a uma reflexão sobre o pensamento dual que caracteriza o caráter hierárquico da inter-relação homem/mulher a partir de palavras que dão significados ao que se compreende pelos termos que definem os dois sexos. Os vocábulos aqui referidos são aqueles que representam ideias opostas, não só no sentido léxico, mas também no que concerne a interpretação social dos atributos que definem homens e mulheres sustentados pela relação dicotômica existente entre eles. O objetivo deste trabalho é investigar a origem e aplicação destas expressões dentro de uma abordagem histórica e sociológica. Para esta análise, então, foi considerada a associação de termos opostos como: racional, superior, forte e externo ao homem e, palavras como: emocional, fraco, inferior e oculto à mulher. Para isso, a definição de família patriarcal, baseada na família estruturada a partir do poder do homem culminando na "inferiorização" da mulher, também foi levada em conta, desde sua origem no ambiente rural até seu reflexo na esfera urbana. Apoiado nestas premissas e conceitos, o presente artigo baseia-se na metodologia de análise do conteúdo das respostas de assentados e assentadas de três projetos de assentamento (P.A.) localizados no estado de Sergipe a fim confrontar a teoria mencionada acima com as afirmações obtidas após categorização por sexo. Foram analisadas respostas dadas por homens e mulheres separadamente a partir dos dados coletados em uma pesquisa realizada no ano de 2009 e que resultou em tese de doutorado ${ }^{3}$. A intenção do artigo é buscar uma possível desconstrução da dualidade homem/mulher de caráter valorativo presente nas suas falas propondo ao leitor uma reflexão crítica sobre a prevalência do caráter "inferior" dado as mulheres, no sentido de desconstruir a relação emoção e inferioridade uma vez que este não é um dado biologicamente atribuído ao sexo feminino, mas sim, uma construção social.

Palavras-chave: Mulher. Gênero. Dominação. Dualidade. Assentamento.

\footnotetext{
${ }^{1}$ Mestranda do departamento de economia doméstica Universidade Federal de Viçosa - UFV. fchiozzini@ hotmail.com.

2 Professora do departamento de economia doméstica Universidade Federal de Viçosa - UFV. juma3870@gmail.com.

3 Os dados deste artigo fazem parte da pesquisa, que resultou na Tese de Doutorado intitulada: "Do acampamento ao assentamento: uma análise da reforma agrária e qualidade de vida em Sergipe", defendida em 2009 no Departamento de Geografia da Universidade Federal do Sergipe.

Revista Ambivalências

V.4 4 N.7 • p. $288-308 \cdot$ Jan-Jun/2016

ISSN 2318-3888 • DOI: 10.21665/2318-3888.v4n7p288-308
} 


\section{ABSTRACT}

The present article invites the reader to a reflection about the dual thought that characterizes the hierarchical character of the inter-relation men/women from words that represent what is understood by both sex. The terms mentioned represent opposite ideas, not only in the lexical sense but also in what concerns the social interpretation of the attributes that define men and women sustained by the dichotomy relation between them. The goal of this study is to investigate the origin and the application of these expressions in a historical and sociological approach. To this analysis the association of opposite terms such as rational, superior, strong, external to men and emotional, weak, inferior and internal to women was taken account. For that, it was considered the patriarchal family definition based on the family structured by the power of the men culminating in the women "inferiority". It was also considered its origin in a rural environment and its reflection in the urban society. Supported by these quotes, the present article used the methodology of content analysis based on the answers of the settlers who live in a Settlement Project (SP) placed in Sergipe, Brazil in order to confront the mentioned theory to their answers categorized by gender. Men and women answers were separated addressed from data collected from a research carried out in 2009 that resulted in a PhD theses. This article intends to research the possible deconstruction of the duality men/women understood in a scheme of values presented in their speech and to propose a critical thought about the women inferiority aiming to deconstruct the relation emotion inferiority since this is not biologically attributed to female sex, but a social construction.

Keywords: Gender. Women. Domination. Duality. Settlement. 


\section{Introdução}

A questão de gênero permite diversificadas abordagens de trabalho, uma vez que se trata de uma categoria de classificação sustentada pela escolha de autores que dedicaram suas obras a esta temática possibilitando assim, os mais distintos vieses orientados pelas relações entre homens e mulheres.

O uso desta categoria destaca relações que envolvem o sexo, mas não são determinadas por ele, necessariamente, pois rejeita as justificativas biológicas e se sustenta nas construções sociais, base das identidades e papéis desempenhados por homens e mulheres.

Assim, a compreensão de gênero sugere, a partir da dualização da diferença entre sexo masculino e feminino, uma forma de dar significado a um tipo de relação de poder. Então, levantar um estudo sob a perspectiva teórica de gênero é considerar que os papéis ocupados por homens e por mulheres são socialmente construídos a partir de uma relação dicotômica e como todas as dualidades, gera dois polos, sendo um superior ao outro. Isto se sustenta pelas correntes pósestruturalistas ${ }^{4}$ de Derrida e Foucault, que destacam a necessidade de pensar gênero de maneira dual, como um binômio homem/mulher, masculino/feminino.

Nesta mesma linha, encontra-se Bourdieu (1999). Em sua obra "A dominação masculina", o autor ilustra de uma maneira muito interessante e axiomática, a dualidade na qual se fundamenta a relação homem/mulher enquanto dominador/submisso. O autor atrela esta dualidade à questão da inconsciência e infantilização do indivíduo, uma vez que, para ele, o indivíduo reproduz inconscientemente o caráter "superior" que a sociedade confere ao homem, e da mesma forma, a mulher é socialmente interpretada como submissa.

Além desta dualidade legitimada na sociedade ocidental através da repetição, a história brasileira tem o patriarcalismo como base de modelo familiar. Considerando a compreensão de família patriarcal

\footnotetext{
${ }^{4}$ Conjunto de investigações filosóficas contemporâneas que negam o estruturalismo e recusam aos fundamentos tradicionais da filosofia, como as ideias de verdade, objetividade e razão.
} 
como aquela composta pela relação dominantes e dominados, observase um modelo baseado na estrutura social da escravidão dentro do período colonial substanciada pelo homem como o detentor do poder, neste caso, o pai, que possui em seu entorno os filhos, a esposa e demais agregados.

É nesta esfera que foi construído o objetivo deste trabalho. O que se propõe aqui é uma reflexão sobre o caráter valorativo da relação dicotômica homem/mulher com base em Bourdieu (1999), Scott (1995) e levando em conta o patriarcalismo de Freyre (1957) a fim de apresentar uma nova abordagem da relação entre homens e mulheres sustentada em uma perspectiva de valores igualitários entre eles.

Inicialmente, no primeiro tópico, esta produção apresenta a relação entre rural e urbano com o intento de contextualizar o objeto de estudo. Ao considerar a mútua influência entre rural e urbano, mais precisamente uma urbanização do rural, pode se questionar se tal influência ocorre apenas nos meios de produção e nos tipos de produtos finais do campo, ou se pode ser percebida também na maneira de pensar da população rural.

Em um segundo momento, foi feita uma reflexão das ideias de Bourdieu (1999) e autores como Wilshire (1997), que investigaram a dicotomia homem/mulher. O interesse com isso foi observar a reprodução destas ideias na prática e sugerir uma possível desconstrução.

No terceiro tópico, as respostas de alguns assentados e assentadas de três Projetos de Assentamentos (P.A) em Sergipe, P.A. Pioneira (Poço Redondo), P.A. José Gomes da Silva (Lagarto) e P.A. Caípe (Nossa Senhora das Dores), foram analisados. Por fim, as considerações finais.

A inquietação que move a ideia central deste artigo baseia-se em levantar razões históricas que fundamentam o caráter negativo, inferior, oculto, fraco e ignorante atrelado à mulher, enquanto que ao homem concerne o oposto, o sinal positivo, superior, evidente, forte e sábio. Ser diferente biologicamente em hipótese alguma é sinônimo de inferioridade ou superioridade. Será que o sexo biológico realmente responde ao que se representa pela identidade de gênero? Por que a 
insistência na valorização? Por que essas discrepâncias nos discursos não são simplesmente complementares?

A análise da relação dual entre homens e mulheres no que tange à ideia da racionalidade masculina frente à emoção feminina foi feita com base, principalmente, na tese intitulada "Do acampamento ao assentamento: uma análise da reforma agrária e qualidade de vida em Sergipe" da Professora Júnia Marise Matos de Sousa defendida no ano de 2009 como requisito para o título de doutora na Universidade Federal de Sergipe. A autora entrevistou moradores de nove assentamentos rurais na região do Sergipe e classificou as repostas nas categorias homens e mulheres. As questões se referiram a aplicação de políticas públicas para a reforma agrária, porém, o objetivo das questões feitas era abordar o sentimento e as impressões dos moradores que compunham estes assentamentos.

Para melhor compreender seu sentimento, a autora propôs aos entrevistados basicamente três classificações de perguntas. A primeira em relação ao que eles consideravam que já possuíam, a segunda se referia ao que eles queriam alcançar e a última, o que eles acreditavam que deveriam fazer para que seus objetivos fossem atingidos. $\mathrm{O}$ presente artigo, contudo, debruçou-se sobre a segunda questão, ou seja, o desejo dos moradores e moradoras dos assentamentos.

Os dados desta pesquisa foram coletados no período de 2008 a 2009 , com objetivos de reflexões diversas, entre eles o intuito de compreender qual a realidade da reforma agrária implantada, quais as perspectivas apontadas pelas famílias e quais as alternativas para alcançar a realidade desejada. A metodologia utilizada para a coleta destes dados consistiu na realização de Oficinas Diagnósticas, utilizando a ferramenta "Matriz Realidade, Processo e Desejo", que foi construída de forma participativa com as famílias. Neste artigo focamos nas aspirações destas famílias, homens e mulheres, em separado, destacando seus desejos e aspirações para uma vida melhor nos assentamentos em que vivem, foco no elemento "Desejo".

As famílias participantes foram constituídas a partir de uma amostra não probabilística do tipo intencional por acessibilidade, uma vez que esta etapa da pesquisa tinha como objetivo maior qualificação dos dados. No P.A. José Gomes da Silva, participaram da Oficina 
Diagnóstica para a construção dos dados, 12 homens e 12 mulheres. No P. A. de Caípe, participaram 07 mulheres e 13 homens. Por fim, no P. A. Pioneira participaram 12 homens e 12 mulheres.

A escolha da problemática se deve a classificação das repostas dadas por gênero. Observou-se que em muitos dos assentamentos, enquanto os homens almejavam objetivos concretos como: trator, campo de futebol, reformas nas casas e na cidade, escola, posto de saúde e médicos, por exemplo, as mulheres, apesar de compartilharem muitos destes desejos, principalmente aqueles que comportam à esfera doméstica e familiar, almejavam questões mais subjetivas, tais como: serem ouvidas, solidariedade, união, representação e boa vizinhança. Isto posto, configura-se a mulher como emocional, fraca, incapaz, sonhadora, e o homem como racional, forte, eficiente e realista, mas querer ser ouvido e se preocupar com união e representação é sinônimo de fraqueza?

\section{Do rural ao urbano: a contribuição da pluriatividade}

Desde os tempos coloniais, as esferas opostas do doméstico e público são estabelecidas pela divisão sexual do trabalho e pela atribuição de determinados papéis no contexto familiar brasileiro. Tanto na cidade como no espaço rural, ao homem cabe o papel de chefe da família e do controle da produção agrícola, enquanto a mulher, sem autonomia e capacidade de escolha, tem sua autoridade estabelecida nas atividades domésticas, como cozinhar, lavar e cuidar das crianças (FREYRE, 1975 apud BRANCO, 2000)

Entretanto, novos fenômenos passaram a ser verificados no Brasil, sobretudo a partir dos anos de 1990. Um período de redemocratização que marca o reconhecimento do trabalhador rural dentro das políticas públicas, como o Pronaf (Programa Nacional de Fortalecimento da Agricultura Familiar), criado em 1996, com o intuito de oferecer crédito aos agricultores familiares a fim de inseri-los em um mercado mais competitivo e modernizado.

Este fato apresenta significativas mudanças que condicionaram uma aproximação do rural e do urbano, no que se refere ao acesso e 
conhecimento de técnicas, culminando em atividades não exclusivamente agrícolas na implementação no setor rural, ou seja, o nascimento das famílias pluriativas ${ }^{5}$.

Esta terminologia é utilizada para expressar a participação cada vez maior de atividades não agrícolas e multifuncionais, dotadas de outras funções sociais, junto da tradicional produção de alimentos (SIMIONI, 2013) principalmente em regiões desfavoráveis para a intensificação da agricultura, como, por exemplo, nas zonas montanhosas. Outro exemplo de pluriatividade é evidenciado pelas atividades associadas à exploração turística ou à comercialização de "produtos da fazenda", como queijos, iogurtes, geleias, sucos de fruta, congelados, etc (CARNEIRO, 1997).

O crescimento da chamada pluriatividade apresenta uma interação entre o rural e o urbano no que tange, principalmente, a economia e, considerando que o espaço rural vem sofrendo uma série de mudanças, seu conteúdo social vem sendo colocado em xeque (MACHADO, 2007). Uma causa desse fator é o estreitamento das relações de mútua influência entre o rural e o urbano de caráter não unilateral, como Machado (2007) pareceu sugerir. Esta inter-relação, nos dias de hoje, caracteriza uma reestruturação do espaço rural remetendo a uma reflexão a respeito da efetividade das atividades agrícolas da unidade de produção frente às expectativas da nova dinâmica do espaço rural. Entretanto, as relações familiares, em especial, as relações entre homens e mulheres, não apresentam indícios desta inter-relação, pois ainda denotam características fortemente baseadas nas relações duais de poder (SIMIONI, 2013).

Mudanças de hábitos, costumes, e mesmo de percepção de mundo, ocorrem de maneira irregular, com graus e conteúdos diversificado, segundo os interesses e a posição social dos atores, mas isso não implica uma ruptura decisiva no tempo nem no conjunto do sistema social (CARNEIRO, 1997, p. 54).

Carneiro (1997) propõe um reforço da identidade dualista entre rural e urbano ao afirmar que as novas experiências advindas do urbano para

\footnotetext{
${ }^{5}$ A estrutura de produção pluriativa refere-se ao exercício de múltiplas atividades por pessoas que pertencem a uma mesma família que vive na unidade produtiva (SIMIONI, 2013, p. 5).
} 
o rural não são apenas ferramentas, mas novas necessidades econômicas, e sugere que elas contribuíram para criar uma diversidade social e cultural ampliando as redes sociais entre estes dois espaços (CARNEIRO, 1997). Esta nova rede contribuiu para trocas de experiências e pensamentos, porém, a questão é se tais trocas foram ou estão sendo profundas o suficiente para substituir o pensamento patriarcal típico da sociedade rural (FREYRE, 1957) por uma ideia de relações entre homens e mulheres desvinculada da desvalorização do trabalho feminino (SCOTT, 1995).

Martine (1992) agrega informações através de uma possível resposta ao afirmar que devido a rapidez do processo de urbanização no Brasil, fator que dificultaria a mudança raciocinada de ideais, o pensamento patriarcal ainda se faz presente, mesmo não sendo mais aquele patriarcalismo que se apoiava na necessidade do estabelecimento de estrutura econômica latifundiária dentro da família do início da colonização.

A urbanização modificou o exercício do poder patriarcal, tornando-o impessoal, abstraindo-o da figura do patriarca. Pode-se sugerir a tese de que o Estado moderno roubou este poder na figura pessoal de quem o exercia. Nossa investigação demonstra que a urbanização mudou a relação entre os sexos, diminuindo os excessos do patriarca, pois limitou seu poder. As modas, os romances, os bailes e o teatro se tornam mais importantes do que a igreja. Neste contexto um novo mundo estava se abrindo para as mulheres (SOUZA, 2000, p. 239).

A esposa dócil, submissa, ociosa e indolente, cuja importância era assumida na educação do filho e gerenciamento da casa caraterizada por Freyre (1990) ainda está presente na sociedade brasileira, pois os relacionamentos entre homens e mulheres dentro de casa são marcados pela dominação e autoridade originárias da cultura patriarcal. Tal fato é refletido nas construções dos papéis nos domínios doméstico e público presentes na sociedade ocidental contemporânea que confirmam esta dualidade. Pois, ainda que os efeitos da expansão do processo de trabalho e da produção capitalista tenham sido intensificados pelos mecanismos da globalização, as transformações do pensamento que sustenta a vida no campo não se dissolveram do agrário (CARNEIRO, 1997), isto é, da reprodução social do ideal 
típico rural baseado na tradição de separação de espaços em masculino e feminino originárias da construção familiar patriarcal.

Para isso, convém reforçar que a definição de família patriarcal proposta por Gilberto Freire (1957) sustenta-se na composição familiar em que o pai detém total autoridade, ou seja, o homem ocupa o papel de dominador perante todos que habitam naquele determinado lar, restando à mulher a submissão. Esta construção familiar representa o modelo tradicional da família brasileira. Freyre (1957) afirma:

A verdade, porém, é que nós é que fomos os sadistas [...] nem o branco nem o negro agiram por si, muito menos como raça, ou sob a ação preponderante do clima, nas relações de sexo e de classe que se desenvolveram entre senhores e escravos no Brasil. Exprimiu-se nessas relações o espírito do sistema econômico que nos dividiu, como um Deus todo-poderoso, em senhores e escravos. [...] (FREYRE, 1957, p. 361).

De acordo com o pensamento científico freyriano, entretanto, consubstanciado na figura masculina e feminina como contrapontos, nota-se seu interesse na definição da construção dos ethos $^{6}$ feminino e, a partir disso, as relações de gênero no Brasil colonial e pós-colonial.

A mulher, então, que sempre pouco conheceu sobre autonomia, simplesmente aceita seu papel inferiorizado, pois, dessa forma e com esse intento ela foi criada, sem ferramentas para sozinha modificar esta condição, uma vez que sua situação é reforçada dentro de sua família, inclusive por outras mulheres. A "mulher não possui autonomia, porque está sendo controlada por uma consciência que ela considera soberana" (BEAUVOIR, 1967, p.63).

\section{Bases da dominação: Bourdieu e a dicotomina mulher emoção e homem razão.}

Arraigado à construção do que Beauvoir (1967) denomina de consciência soberana e submissa, a sociedade ocidental contemporânea

${ }^{6}$ Ethos é uma palavra com origem grega, que significa "caráter moral". Usada neste trabalho para descrever o conjunto de hábitos ou crenças que definem a comunidade feminina. 
compreende mulheres e homens como responsáveis por papéis diferentes dentro dos seus campos de atuação, porém, o que se nota é que tais papéis não são pacificamente compreendidos como complementares dentro de um campo ${ }^{7}$ de atuação.

Para ilustrar este fato, Wilshire (1997) em seu artigo "Os usos do mito, da imagem e do corpo da mulher na re-imaginação do conhecimento" descreve a relação dicotômica entre o homem e a mulher. A mulher é descrita como a porção corpo: sensualidade, natureza e emoção em relação ao homem com sua representação nas palavras: mente, ideias, cultura e razão. Esta relação pode ser ilustrada pela incumbência da maternidade e da função de protetora da família como automaticamente relacionadas ao emocional e ao cuidado, enquanto que os homens, com base na sua trajetória de caça e provisão do alimento, são relacionados com a força e coragem.

Pierre Bourdieu (1999) apresentou a mesma relação dicotômica em sua obra "A dominação masculina". A partir de seu estudo sobre as relações duais entre homens e mulheres na sociedade Cabila na Argélia, o autor descreveu a oposição do masculino, alto, reto, claro, público, frente às mulheres, que para ele representavam o baixo, curvo, escuro e privado. A partir de suas observações, entretanto, Bourdieu (1999) questiona se tal dicotomia se repete também na nossa sociedade.

Esses esquemas de pensamento, de aplicação universal, registram como que diferenças de natureza, inscritas na objetividade, das variações e dos traços distintivos (por exemplo, em matéria corporal) que eles contribuem para fazer existir, ao mesmo tempo que as "naturalizam", inscrevendo-as em um sistema de diferenças todas igualmente naturais em aparência; de modo que as previsões que elas engendram são incessantemente confirmadas pelo curso do mundo [...] (BOURDIEU, 1999, p.15).

Bourdieu (1999) define esta distinção como natural, pois é a partir dos atributos biológicos de cada um dos pares é reconhecido, cada qual a seu modo de se sustentar no “jogo inesgotável de práticas e metáforas;

\footnotetext{
${ }^{7}$ Definição de Bourdieu (2007) para explicitar as forças atuantes em um mercado de troca que representam símbolos atuantes em um mesmo espaço que uma hierarquização de valores.
} 
e também suficientemente divergentes para conferir, a cada uma, uma espécie de espessura semântica, nascida da sobre determinação pelas harmonias, conotações e correspondências" (BOURDIEU, 1999, p.16). Para ele ainda, tais características biológicas representam simbolicamente a relação dominador e submisso através dos seus significados imbuídos.

É nesse ínterim que tal autor sugere a inconsciência da relação social de dominação com a qual os indivíduos convivem sem questionamento, ações apresentadas pelos homens e pelas mulheres compreendidas como naturais, enraizadas na repetição, ou seja, o que o autor denomina de Habitus.

[...]um sistema de disposições duráveis e transponíveis que, integrando todas as experiências passadas, funciona a cada momento como uma matriz de percepções, de apreciações e de ações - e torna possível a realização de tarefas infinitamente diferenciadas, graças às transferências analógicas de esquemas[...] (BOURDIEU, 1999, p 63).

Realizadas de uma maneira impensada, apenas reexecutadas devido à falta de conhecimento e de outra alternativa, as ações e ocupação de papéis dentro e fora de casa legitimam a construção social dual valorativa entre homens e mulheres fazendo coro com a contribuição cultural que o patriarcalismo trouxe para a nossa sociedade.

Em se tratando do Brasil, mais precisamente região nordeste ${ }^{8}$ que apresenta um dos menores índices de renda, a submissão feminina nas relações de trabalho e no contexto familiar é reforçada ainda na contemporaneidade pela reprodução social. Dubar (1997) considera que as "abordagens culturais e funcionais da socialização acentuam uma caraterística essencial da formação dos indivíduos" desde seu modo de ser e de agir. Para este autor, socialização é qualquer forma de interação social enraizada em um comportamento inconsciente seguido por cada indivíduo que aceita se adaptar à cultura do grupo pertencente à sociedade à qual se encontra (DUBAR, 1997).

\footnotetext{
${ }^{8}$ Censo do IBGE 2010 indicou que dos 50 municípios mais pobres do Brasil, 32 estão na região nordeste.
} 
Esta é a razão da escolha de Gilberto Freyre (1957) para junto com Bourdieu (1999) sustentar teoricamente uma possível origem e compreensão da construção da inferioridade feminina.

Freyre foi um sociólogo que se dedicou a escrever sobre o processo civilizador da sociedade brasileira. Autor que muito colabora com este artigo ao utilizar-se do estudo dos costumes e outros elementos que caracterizam a distinção social no Brasil considerando a formação da sociedade brasileira como originada no meio rural.

Da mesma forma, contribui Bourdieu (1999), que ao apresentar seu conceito de dominação, explica a lógica do impensado, isto é, de onde se origina esta aceitação e discute a necessidade da mulher se libertar da passividade a que está submetida. Para ele, é a partir da desnaturalização da dualidade dominado-subordinado que uma nova concepção de relação social de gênero seria possível. Entretanto, Bourdieu (1999) prossegue sugerindo que esta mudança apenas ocorreria em âmbito maior quando instituições sociais como: escola, igreja, locais de trabalho, entre outros, também a reproduzirem.

\section{Análise das respostas dos moradores dos assentamentos sob as lentes teóricas de gênero.}

Pierre Bourdieu (1989) aborda os termos "discursos", "história reificada", "representações do mundo social" e "visões de mundo" a fim de exteriorizar as consciências particulares dos indivíduos visando explicar o mundo social através de suas percepções. Assim, para entender o pensamento de Bourdieu (1989), cabe observar como ele trata as ideias e representações que constituem a subjetividade dos agentes sociais e suas ações.

O discurso, para este autor, seria então a "história reificada", "a história que se acumulou ao longo do tempo nas coisas, máquinas, edifícios, monumentos, livros, teorias, costumes, direito, etc." (BOURDIEU, 1989, p.82). Este acúmulo de informações, então, solidifica o que é exteriorizado pelos grupos pertencentes a uma instituição ou outra através de seu discurso. 
É por esta razão, então, que as falas dos assentados dos três assentamentos analisados neste artigo foram investigadas e utilizadas como ferramenta para a análise do teor dicotômico do que a sociedade compreende como "história" reificado por homens e por mulheres.

Nesta toada, a tradição filosófica continua a exaltar que há coisas que são percebidas como masculinas a outras como femininas (WILSHIRE, 1997), assim, no campo feminino estariam as questões pertinentes a mente e do lado masculino, a matéria. "Durante a revolução científica, ainda se pensava que alma e mente só podiam se realizar em seres masculinos e que a alma tinha que lutar para subjugar o corpo" (WILSHIRE, 1997, p. 103).

É socialmente esperado que enquanto o homem se preocupe com questões práticas, lógicas e de raciocínio, a mulher esteja destinada ao papel de protetora e emocional, com grande preocupação na família e filhos. Destarte, quando as respostas dos moradores e moradoras do assentamento são apresentadas, observa-se uma confirmação deste raciocínio.

Sousa (2009) autora da pesquisa na qual os dados deste artigo se baseiam, categorizou as respostas dos assentados do projeto de Assentamento (P.A.) Pioneira em Sergipe por sexo. Segundo os resultados obtidos, os homens almejam:

Associação legalizada; casa precisando de reforma; calçamento; creche; igreja; quadra de esporte; trator; terno e bola para comunidade; posto telefônico; projetos para a comunidade; teatro para animar as crianças; médico e posto de saúde; projeto de irrigação; praça. (ASSENTADO, P.A. PIONEIRA, 2009).

A resposta do assentado demonstra sua preocupação com assuntos que se referem à organização e construção do assentamento, de uma maneira estrutural, como o bom funcionamento e progresso do espaço. $\mathrm{O}$ assentado parece se preocupar com a modernidade do espaço, além do acesso a outras localidades e comunicação, questões que de forma geral contribuem para a modernização da localidade. Além disso, seu discurso demonstra preocupação com lazer esportivo, questão comum para pessoas que não precisam dedicar seu tempo a família e filhos com muita intensidade, pessoas que possuem tempo livre, além de que o interesse em praticar esportes como futebol evidencia o interesse 
masculino em realizar atividades coletivas, atividades em grupo preenchendo seu tempo livre com outros homens, o que o afasta do trabalho na casa e com a família, uma vez que futebol é uma solicitação típica masculina.

Por outro lado, dentre os desejos de uma assentada do mesmo P.A., percebe-se intenções diferenciadas:

Posto de saúde; pavimentação das ruas; praça; igreja; trabalho; escola noturna para os adultos; casas para os filhos dos assentados; orelhão; quadra de esportes; parque de diversão; creche; trabalho para os filhos dos assentados; campo de futebol e bolas; mais "bolsa família", rede de esgoto; dinheiro; equipe da dengue visitando o assentamento; chuva; computadores na comunidade; atendimento odontológico; projeto; associação melhor; melhores merendas escolares; união e saúde; ampliação das series escolares no assentamento (ASSENTADA, P.A. PIONEIRA, 2009).

Nesta reposta, pode-se perceber uma maior preocupação com a família em relação a resposta analisada anteriormente. Ao reivindicar casa para os filhos dos assentados, atendimento odontológico, mais "bolsa família", projeto, união e saúde, a assentada mostra-se interessada no bem-estar da comunidade em geral incluindo os seus familiares, uma atitude que corrobora com o que se espera de uma mulher, mãe e esposa, ou seja, o papel de cuidador está sendo desempenhado. Além disso, é parte de seu interesse ainda, que haja melhoria no que concerne às crianças propriamente, nas creches, parque de diversão e merendas escolares, isto é, âmbitos do que é compreendido socialmente como responsabilidade da mãe ao envolver cuidado.

Dentro da concepção de mãe cuidadora, é da mãe que a sociedade cobra o preparo da alimentação dos filhos, o cuidado assistencial do dia a dia, cuidado com a saúde. Então, ao contar com o auxílio de uma boa merenda escolar, uma boa creche e parque de diversão onde a criança possa passar parte de seu tempo livre, a mãe está compartilhando sua "tarefa" com outras instituições. Assim, também, esta mãe pode se dedicar aos seus serviços domésticos com mais assiduidade e tranquilidade.

Além disso, a mulher ao desejar campo de futebol e bola, evidencia um outro papel para o qual "foi criada" que é o papel de companheira do 
marido não só na rotina diária, mas nos seus interesses. A mulher é a companheira, a conivente, aquela que "coloca o desejo da família frente ao seu", mesmo que o inverso não ocorra, ainda porque o inverso não é esperado. Assim, ao saber que seu marido deseja que na sua vizinhança exista um campo de futebol, a mulher se mostra totalmente a favor deste movimento mesmo sem saber ao certo o que isso acarretaria a ela.

No Projeto de assentamento (PA) Caípe, também se nota discrepância entre as respostas de homens e mulheres, nas repostas dadas pelas mulheres e pelos homens, observa-se uma distinção com base no gênero.

Oculista; trator; orelhão; recursos; melhorias na sede; irrigação; responsabilidade dos associados; posto médico; presença de técnicos; anistia das dívidas; igreja; açude nos lotes; melhores estradas; curral comunitário. (ASSENTADO, P.A. CAÍPE, 2009)

O trabalho e a produção são fatores muito priorizados pelos assentados. Ao requerer oculista, trator, irrigação, presença de técnicos, o assentado demonstra preocupação na sua produção, o interesse em um oculista e posto médico podem demonstrar sua preocupação com a visão e saúde que auxiliariam no seu rendimento enquanto produtor. Então, seu interesse na saúde parece estar estritamente atrelado ao trabalho, o que representa um raciocínio prático, condizendo às características atribuídas ao homem.

$\mathrm{O}$ assentado ainda evidencia seu interesse na comunicação com outras áreas, o espaço externo, o público que é espaço masculino (HABERMAS, 2003) ao mencionar a necessidade de melhores estradas e orelhão.

Por outro lado, o depoimento de uma assentada do mesmo P.A. apresenta outros interesses:

Mais união da comunidade; recursos para trabalhar com artesanato (crochê); água encanada (não apenas no poço); reforma na sede do centro comunitário; mais higiene na comunidade; recursos para criar gado; recursos para a produção de doces; banheiro na sede do centro comunitário; mais cuidado com o lixo das casas; recursos para reformar as casas; emprego; atendimento de dentista; 
creche para as crianças (ASSENTADA, P.A CAÍPE, 2009)

As mulheres tendem a enfatizar as plantações, cultivos, programas do governo a fim de possibilitar alimentação a suas famílias, igreja e educação para os adultos. Questões fundamentais como casa, escola também foram assinaladas, além de apresentarem-se satisfeitas ao admitirem que possuem boas relações com vizinhos e paz. Além de, ao pensarem em trabalho, apresentarem alternativas que não as retirem do ambiente doméstico, como o artesanato. Com este tipo de atividade, ela pode contribuir financeiramente em suas casas e ao mesmo tempo estarem presentes para as funções domésticas, reforçando a construção social do "lugar" da mulher.

Aprender artesanato; atendimento de oculista e acesso a óculos; associação para mulheres; emprego para os filhos; igreja; uma praça e quadra de esporte; clube de mães; lazer para as crianças; cemitério; creche; calçamento; ter médico e dentista, posto e ambulância (ASSENTADA, P.A. JOSÉ GOMES DA SILVA, 2009).

$\mathrm{O}$ artesanato aparece novamente como alternativa de trabalho, e com isso o interesse em se reunirem e se fortalecerem nos mesmos ideais, como um grupo de mulheres e mães. Elas pedem por praças, associação para mulheres e lazer para as crianças, ou seja, demonstram interesse em se reunirem em um grupo que as represente almejando assim, uma identidade.

Entretanto, mesmo demonstrando certa satisfação com o que possuem, as mulheres não deixam de desenhar as limitações que impedem que suas condições de moradia sejam melhores. Dentre elas estão: necessidade de reformas nas casas e nas ruas, questões pertinentes a saúde como médicos e postos de saúde, atividades para as crianças, água encanada

Mulheres e homens em alguns momentos objetivam muitas coisas em comum a eles, mas a ênfase das mulheres é que suas expectativas sejam ouvidas, que haja solidariedade, participação das mulheres e dos jovens nas reuniões, diálogo, organização, seriedade, união, companheirismo e mais compreensão. Ou seja, questões que os homens não mencionam e que confirmam o interesse particular das mulheres em questões de relacionamento. 
A princípio esta observação confirmaria a posição da mulher na sua posição inferiorizada, emocional e abstrata em relação à praticidade do homem. Frente a isso, uma nova compreensão desta situação pode ser proposta. A mulher imbuída das suas caraterísticas "naturais" poderia estar apontando, ao contrário do que se conclui a princípio, um ato de coragem, quebra de barreiras e de busca pela conquista de uma maneira mais ponderada, pacífica e, por fim, mais eficiente. Esta seria uma nova perspectiva para a interpretação da dicotomia da qual a mulher e o homem participam e onde cada um ocupa e sustenta seu papel de inferior e superior respectivamente.

Esta nova perspectiva eleva a mulher à categoria pensante, tirando-a do segundo lugar de coadjuvante. Uma vez que a condição de superior e inferior é uma construção social, ela pode ser modificada. Evidentemente este é um caminho longo e turbulento, mas com base na capacidade da mulher de propor soluções mais pensadas do que agidas poderia repercutir positivamente.

\section{Considerações finais}

Após apresentadas diversas questões levantadas ao longo deste texto, cabe propor algumas notas finais para reflexão a respeito da desconstrução do caráter valorativo desta dualidade como uma proposta inovadora para os estudos de gênero.

Com este intuito, três conjuntos de questões foram pontuados neste trabalho. O primeiro deles segue a respeito da posição da mulher na estrutura de dominação, uma posição legitimada na condição de inferioridade com bases em construção culturais e sociais que reforçam esta situação, através da repetição de ideias advindas da reprodução social passada de uma geração para a outra. Entretanto, uma vez que esta construção é cultural e a antropologia nos ensina que existem muitas sociedades com distintas culturas, pode se entender que esta construção pode ser alterada, até mesmo porque o que é construído pode ser desconstruído.

No entanto, em muitas culturas, a mulher ocupa a posição inferiorizada. Nestas sociedades, não cabe a ela o domínio de seu 
próprio corpo, a escolha do marido, tão menos decisões de âmbito político e social. Tratam-se de sociedades que apresentam a mulher construída historicamente como um indivíduo não dotado de atributos capazes de contemplá-lo com o poder decisório, uma vez que seguindo um percurso histórico, nota-se que a mulher não detinha bens e muitos direitos, como direito ao voto e direito de decisão quanto ao seu casamento. A mulher passou a ser vista como um indivíduo apenas após as manifestações do movimento feminista, iniciado no final do século XVII, enquanto para o homem estas questões jamais foram problemáticas.

Assim sendo, a mulher não carrega este status ativo na sociedade, haja vista hoje ela seja mais participativa, entretanto a memória social arrasta o pesado fardo de sua passividade social. Dessa forma, sua condição inferiorizada de cunho cultural ainda é reforçada, não só pelos homens, mas por elas próprias, o que dificulta, todavia, a construção de um novo paradigma.

O segundo ponto para o qual este trabalho pretende chamar atenção refere-se a uma primeira ideia para estudos futuros. Tomando por base o conceito de relação dicotômica de Bourdieu (1999), a ideia é propor a desconstrução do caráter negativo dado ao feminino em comparação a classificação positiva atribuída aos homens. A intenção é que uma nova consideração seja feita a fim de se entender as definições de homens e mulheres como complementares sem relação de valores, hierarquização e distribuição desigual de poder e direitos.

Dessa forma, refletir sobre uma possível desconstrução da associação dicotômica mulher/emoção e homem/razão, apresentada através da reprodução de um ideal patriarcal, é desassociar a mulher de seu corpo, do fator biológico que a define exteriormente como frágil, menos capaz, interna, o não homem. Como sugere Bourdieu (1999), ao desconstruir esta associação, a mulher ganha possibilidades de ação e participação no cenário social e político.

Uma terceira abordagem muito instigante seria com relação à preocupação a partir do olhar das mulheres rurais que se organizam como membros de movimentos de mulheres trabalhadoras rurais, como o Comitê de Mulheres do Condraf (Conselho Nacional de 
Desenvolvimento Rural Sustentável) e de empresas públicas prestadoras do Ater (Assistência Técnica e Extensão Rural).

Estas organizações justificam a Conferência Temática de Mulheres Rurais, evento que visa evidenciar a necessidade do diálogo com as mulheres rurais devido a sua participação ativa no campo, além de considerar a especificidade da vida da mulher no campo, uma vez que esta possibilidade envolve uma produção muito mais de autosustentação para famílias e comunidades.

A partir desta tendência, observa-se uma outra sugestão para trabalhos futuros, com o olhar voltado para a soberania alimentar, cuidado familiar e com o meio ambiente, além de dar poder a mulher proporcionando, desta forma, a possível construção de um novo paradigma no que tange às questões de gênero.

Entretanto, tomando como referência as respostas obtidas pelos moradores e moradoras dos assentamentos e sua região de localização, observa-se preocupações em comum com questões que concernem reformas da casa e da cidade, construções e produção rural, assim como, assuntos de bens comuns para a população: saúde, educação, transporte e recreação. Ou seja, a disparidade de interesse que levou ao objeto deste artigo ilumina questões teóricas e conceituais que sustentam os termos que definem a dualidade tão mencionada neste trabalho, isto é, interesses concretos dos homens frente aos interesses de cunho abstrato das mulheres.

Certamente, não se trata de caminhar contra teorias, mas sim, repensar o caráter valorativo, como já foi mencionado. É inegável, portanto, que homens e mulheres são diferentes não só biologicamente, mas cultural e socialmente, de uma maneira construída, mas, isso não indica ou deveria indicar que os diferentes sexos deveriam ser tidos como inferiores e superiores um sobre o outro.

A história patriarcal está em nossa origem, nossas famílias ainda carregam esta marca, mas ainda há espaço para novas maneiras de observar as relações entre homens e mulheres dentro e fora do lar. 


\section{Referências}

BEAUVOIR, S. O segundo sexo I - Os fatos e os mitos. São Paulo: DIFEL, 1967.

BOURDIEU, P. A dominação masculina. Rio de Janeiro: Bertrand Brasil, 1999.

2007.

A economia das trocas simbólicas. São Paulo: Perspectiva,

O poder simbólico. Lisboa: Difel, 1989.

CARNEIRO, M. J. Ruralidade: novas identidades em construção. Estudos Sociedade e Agricultura, 11 53-75, Anais do XXXV Congresso da Sociedade Brasileira de Sociologia e Economia Rural: Natal, 1997.

DUBAR, C. A socialização: construções das identidades sociais e profissionais. Porto: Porto Editora, 1997.

FREYRE, G. Casa grande \& senzala: formação da família brasileira sob o regime da economia patriarcal. 50.ed. revista. São Paulo: Global, 1957.

Sobrados e Mucambos: Decadência de Patriarcado Rural e Desenvolvimento do Urbano. RJ/SP: Editora Record, 1990.

HABERMAS, J. Mudança estrutural da esfera pública. Rio de Janeiro: Tempo Brasileiro, 2003.

MACHADO, M. R. I. M. As relações entre o rural e o urbano: um espaço conjunto indissociável em Vitória de Santo Adão, PE. 2007 dissertação de mestrado em geografia bdtd.ibict.br/vufind/Author/Home?author=Rita+Ivo+de+Melo+Macha do\%2C+Maria VISTO EM 08 DE Agosto de 2015.

MARTINE, G. Processos recentes de concentração e desconcentração urbana no Brasil: determinantes e implicações. Documento de Trabalho - no. 11, ISPN, abril de 1992.

SCOTT, J. Gênero: uma categoria útil de análise histórica. Educação e realidade. São Paulo. v. 20, n 2., p. 71-99, 1995. 
SIMIONI, F. J. Determinantes da renda familiar no espaço rural: uma revisão. Organizações Rurais e Agroindustriais, Lavras, v. 15, n. 3, p. 397-410, 2013.

SOUSA, J. M. M. Do acampamento ao assentamento: uma análise da reforma agrária e qualidade de vida em Sergipe. São CristovãoSergipe. 2009. Tese de doutorado, departamento de geografia Universidade Federal do Sergipe.

Modernização seletiva: uma reinterpretação do dilema brasileiro. Brasília: Editora da UnB, 2000.

WILSHIRE, D. Os usos do mito, da imagem do corpo da mulher na re-imaginação do conhecimento. Gênero, corpo e conhecimento. Rio de Janeiro. Record: Rosa dos Tempos, 1997.

Recebido em 03/03/2016

Aprovado em 01/07/2016 